\title{
A Cognitively-oriented Encapsulation of Strategies Utilized for Lexical Development: In search of a flexible and highly interactive curriculum
}

\author{
MoHAMmad MoHSENI-FAR \\ Shahid Chamran University \\ Ahwaz, Iran
}

Received: 5 May 2007 / Accepted: 12 July 2007

ISSN: $1697-7467$

\begin{abstract}
The purpose of this paper is to inquire in depth into vocabulary learning/ acquisition strategies and techniques as related to second/foreign language. In doing so, the study is intended to focus particularly on the variables connected to lexical knowledge and accordingly set up a fairly comprehensive framework which includes and accounts for the most important strategies and pertinent factors within the vocabulary acquisition context. The study presents four salient variables; three from Flavell's cognitive model (1992), and the variable of context is introduced to give meticulous importance to review. The organic notion underlying this investigation is that the most effectual and successful lexical development will occur in multipurpose and highly interactive curriculums that attain a pedagogically well-reasoned equilibrium between explicit and implicit activities for L2 learners at all levels of their progress.
\end{abstract}

Key words: vocabulary learning/acquisition, lexical knowledge, lexical development, strategies and techniques.

RESUMEN: El objetivo de este trabajo es comprobar en profundidad las estrategias y técnicas de adquisición/aprendizaje de vocabulario relacionadas con una lengua extranjera. El trabajo se centra en las variables que tiene que ver con el conocimiento léxico y consecuentemente establecer un marco comprensivo que tenga en cuenta las estrategias más importantes y los factores más pertinentes dentro del contexto de adquisición de vocabulario. El estudio presenta cuatro variables, tres del modelo cognitivo de Flavell (1992) y una cuarta, el contexto se añade para dar más importancia a la revisión. La noción que subyace a esta investigación es que los desarrollos léxicos con mayor éxito se darán en curriculums que ofrezcan múltiples objetivos y que sean muy interactivos para obtener un equilibrio pedagógico equilibrado y bien razonado entre actividades explícitas e implícitas para estudiantes de una segunda lengua en todos niveles de su progreso.

Palabras clave: adquisición/aprendizaje de vocabulario, conocimiento léxico, desarrollo léxico, técnicas y estrategias. 


\section{INTRODUCTION}

Vocabulary acquisition is considered an integral and fundamental area of language teaching/ learning by linguistic researchers. Psychologists, linguists and language teachers have long been interested in vocabulary learning strategies. They have tried to understand the role of the lexicon in language learning and communication. In particular, during the past fifteen years, the field of second language acquisition has witnessed renewed interest in vocabulary learning and acquisition. There are many dimensions to vocabulary acquisition, as reflected in the multitude of different areas of research being done on the topic.

One way to investigate the overall task of vocabulary learning/acquisition is through the distinction between knowing a word and using a word. In operational terms, knowing a word may be seen as a continuum ranging from blurry recognition of its spelling to (semantically, syntactically, stylistically) correct and contextually appropriate productive use. Retrieval of a word from the mental lexicon for productive use requires a higher degree of accessibility or, in other words, a more solid integration in various networks than is needed for receptive use (Groot, 2000:76). In other words, the purpose of vocabulary learning should include both recalling words and the ability to apply them automatically in a wide range of language contexts when the need arises. Vocabulary learning strategies, therefore, have to incorporate strategies for "recognizing and knowing" as well as "using" words. On the other hand, Henriksen (1999) draws attention to the fact that the acquisition of word meaning actually involves two interrelated processes: item learning (adding to the lexical store by creating extensional links, i.e. form-meaning mappings) and system changing (re-ordering/changing the lexical store via network building). The tendency in L2 vocabulary acquisition research has been to neglect the latter and focus on the former.

Another way to view vocabulary learning is to take it as a process of interconnected subtasks. When learners first encounter a new word, they might guess its meaning and usage from accessible tokens. Some learners might resort to consulting a dictionary. Others might make notes in the margins, between lines, or in a separate vocabulary notebook. Some learners will take advantage of simple rote repetition to commit the word to memory. Some would even attempt to use the word enthusiastically in a real context. Each of these task stages demands metacognitive decision, choice, and deployment of cognitive strategies for vocabulary learning. And each technique a learner puts to use will determine to a large degree how and how well a new word is learned/acquired.

This article aims to provide a digest of recent research on vocabulary acquisition and to pinpoint areas that need further exploration. To this end, the researcher centers on one particular area in depth, namely, vocabulary learning strategies. In so doing, it attempts to synthesize for the reader the major and recent findings of research into vocabulary learning and acquisition, and to outline each of the main areas of research on the subject matter.

\section{Critical review of relevant literature}

\subsection{Background}

Mastery of vocabulary is an essential component of second language acquisition. Effective second language vocabulary acquisition is particularly important for English as a foreign 
language (EFL) learners who frequently acquire impoverished lexicons despite years of formal study (Hunt \& Beglar, 2005:1). Today's language teachers and researchers have realized the important role of vocabulary in different pedagogical tasks. There is no doubt that virtually all second language learners and their teachers are well aware of the fact that learning a second language (L2) involves the learning of large numbers of words (Avila \& Sadoski, 1996; Laufer \& Hulstijn, 2001), yet how to accomplish this task is often of considerable concern to them (Ott, Blake \& Butler, 1976:37). How vocabulary is acquired and what the most efficient means are to promote effective acquisition have been worthwhile lines of enquiry in the field of second language acquisition (De La Fuente, 2002:82).

The acquisition of a new lexical item is a complex process. Ellis, Tanaka and Yamazaki (1994:457) argue that vocabulary acquisition involves discovering the frequency with which the item is used in speech and writing, its situational and functional uses, its syntactic behavior, its underlying form and the forms that can be derived from it, the network of associations between it and other items, its semantic features and, of course, the various meanings associated with the item. Thanks to this complexity, research on L2 vocabulary acquisition encompasses a number of different and diverse sub-areas. For example, how words are stored in the mental lexicon, automaticity of retrieval, the role of vocabulary in reading comprehension, the role of background knowledge, the implications of L2 vocabulary acquisition for L1 vocabulary research, how words are learned in context and other strategies for reading in L2 (Chun \& Plass, 1996:184).

Irrespective of the significance of lexical knowledge and vocabulary acquisition, the techniques and strategies recommended in this field are somewhat challenging (Newton, 2001:30; Mohseni-Far, 2006:149). Although researchers and language teachers are becoming more and more convinced that vocabulary knowledge constitutes an essential part of competence in a second or foreign language, so far no comprehensive theories have been proposed that try to explain foreign language growth in terms of lexical development (Bogaards, 2001:321). In spite of the expansion in the amount of empirical research on vocabulary acquisition, consensus is absent over issues such as the conceptualization of the process by which vocabulary acquisition occurs, the importance of context use for acquiring vocabulary, and the amount to which students build up specific strategies for vocabulary learning during their language studies.

In order to conduct the research in a more systematic and logical way, the present researcher takes four prominent variables into account; three from a cognitive model suggested by Flavell (1992), i.e., learner, task, strategy, as a general frame for the research as well as the variable of context. Initially, these four factors are introduced and defined, then in subsequent parts they are dealt with in more detail. Having taken these important variables into consideration, the investigator also tries to shed significant light on major issues and controversies concerning each variable.

\subsection{Learner, task, context and learning strategies}

Learner, task, context, and strategy are interrelated and work together to form the scaffold of learning/acquisition. The strategies a learner exercises and the effectiveness of these strategies very much depend on the learner him/herself (e.g., attitudes, motivation, prior knowledge, 
topic familiarity), the learning task at hand (e.g., type, complexity, difficulty, and generality), and the context or learning milieu (e.g., the learning culture, the influence of input and output opportunities). Therefore, an analysis of learning strategies will never be complete without identifying the learner, task and context configuration of the particular learning situation. Some strategies are more learner-dependent, some are more task-dependent, and others are more context-contingent.

\subsubsection{Learner}

The variable Learner needs to be discussed from different perspectives. The leaner brings to the language learning situation a wide spectrum of individual differences that will influence the learning rate and the ultimate learning result (Gu, 2003:2). The most widely reported learner factors include gender, language aptitude, intelligence, prior knowledge, motivation, self-concept/image, personality, and cognitive and learning style. Motivation, emotion, and socio-cultural factors may affect the way in which humans process information (Laufer \& Hulstijn, 2001:7). The noted learner-dependent factors to a large extent define how a learner handles a task.

\subsubsection{Task}

The conception of the learning task incorporates materials being learned (such as the genre of a piece of reading) as well as the end the learner is attempting to achieve by using these materials (such as remembering, comprehending, or using language). Task can be defined as an activity or action which is carried out as a result of processing or understanding language. Laufer and Hulstijn (2001:17) refine the meaning of task in the field of vocabulary acquisition in particular as "an activity in which meaning is primary".

\subsubsection{Context}

It is necessary to distinguish between two types of context. First, learning context, which refers to the "learning environment and includes the teachers, the peers, the classroom climate or ethos, the family support, the social, cultural tradition of learning, the curriculum, and the availability of input and output opportunities" (Gu, 2003:2). Second, language context, which refers to the textual or discoursal place in which a particular word or structure can be found. Great importance has been attached to the latter by researchers and accordingly it will be subjected to extensive and detailed investigation within this study. In support of the significance of context, Lawson and Hogben (1996:106) suggest that from a psychological as well as a linguistic point of view, underlying the first guideline would be the need for vocabulary to be learned in context. Activities and reading materials that present words in meaningful contexts may contribute to vocabulary gains and are valued highly by students (Zimmerman, 1997:136).

\subsubsection{Strategy}

A learning strategy covers a series of activities and efforts a learner makes to facilitate the completion of a learning task. Vocabulary learning strategies are any set of operations, 
steps, plans, routines used by the learner which affect this process. A technique is initiated when the learner examines the task, the situation, and what is available in his/her own mind. The learner then goes on to select, deploy, monitor, and weigh up the effectiveness of this activity, and decides if s/he needs to revise the plan and action. Theorists now place considerable stress on the importance of foreign language students' developing autonomous learning strategies (Favretti, Silver, Tamburini \& Gasser, quoted in Lawson \& Hogben, 1996:106). Contextual guessing, skilful use of dictionaries, note-taking, paying attention to word formation and contextual encoding are some strategies normally applied by learners. Wenden (1987:6) points out that language learning strategies have to consider different aspects of the language learning process. She identifies three areas in particular that language learning strategies refer to: (a) the actual behaviour of learners (what do learners do to learn an L2), (b) strategic knowledge (what learners know about the strategies they use), and (c) knowledge about aspects (other than strategies) of the L2 learning process, such as personal/motivational factors. These areas are summed up by Rubin (1987) as "what learners do to learn and do to regulate their [language] learning". Language learning strategies are applicable to a wide variety of language learning tasks, ranging from rather discrete and isolated tasks such as vocabulary, pronunciation and grammar to integrative tasks like oral communication and reading comprehension.

\subsection{Task-dependent vocabulary learning strategies}

Vocabulary learning strategies constitute a subclass of language learning strategies which in turn are a subclass of learning strategies in general. Fewer studies can be found on learnerrelated vocabulary learning strategies. Most of the empirical investigations on vocabulary learning strategies in a second language have focused on different sub-tasks of vocabulary learning. The emphasis of the study is placed upon this variable as well.

\subsubsection{Guessing}

The premise underlying this line of research is the belief that the vast majority of words in the L1 come from extensive and manifold exposures through use rather than direct instruction, and therefore vocabulary learning in a second language should follow the same way. A number of topics have often been put forward in the literature: guessing leading to vocabulary learning, inference from context, exposures needed to learn a word, and incidental (implicit) vocabulary learning and intentional (explicit) learning. Each of these questions is critically dealt with below.

\section{Guessing ending in vocabulary learning}

One of the strategies most often discussed in the literature is guessing word meaning from the clues made available by the context. Factors that affect the likelihood of success in inferencing include a context rich enough to provide adequate clues to guess a word's meaning (Celce-Murcia, 2001:290). Put another way, the unknown word to be guessed has to have plenty of comprehensible supporting context (Nation \& Meara, 2002:44). In order to discuss this issue from a pedagogical standpoint, it is better to use the technical alternative "inferring" meaning from the context instead of "guessing". 


\section{Guessing from context [GFC]/ (Inference from context [IFC])}

In a sense, GFC is the mirror image of incidental acquisition on the strategy side. Nation has championed GFC as the "undoubtedly most important vocabulary learning strategy" (1990:130), and recommends GFC especially for low-frequency words as their rarity does not afford the learning effort. One difficulty in this area of research is that there is no standard characterization of what is intended by context. In its broadest sense, of course, context may be said to comprise all the perceived phenomena that accompany the process of a given stimulus, including the physical surroundings in which learning take place (Prince, 1996:479). Using the meanings of words together within the whole meaning of the sentence is the deepest level of processing and ensures the best memory (Cook, 1991:36). Crucial to inferring meaning from context is the degree to which context unveils word meaning. This degree is restricted by the student's own background knowledge and constraints in the text itself. Hence, both teachers and students must be aware that context functions to restrict meaning as well as to reveal it.

Some contexts do not provide a lot of information about a word, but others provide some information that can take knowledge of the word forward. Lawson and Hogben (1996) found a lack of association between GFC and recall of word meaning, which they interpret as emphasizing the need to distinguish the use of GFC for the generation of new word meanings, and their acquisition for subsequent recall. Shu, Anderson and Zhang (1995:79) suggest that significant learning from context is evident only when unfamiliar words appear repeatedly. When a context is rich enough, it will be sufficient to allow a learner to infer the full word meaning. On the other hand, if a context is too simple to understand, then no vocabulary acquisition takes place. For example, at superior levels of proficiency, and when reading for comprehension - rather than to explicitly learn the meaning of unfamiliar words - the context may be easily understood without having to determine the meaning of every unfamiliar word (Pulido, 2003:241). Pulido (2004:472) also states that words that may be easily guessed in the course of reading may not be better retained because of the lack of a need to allocate sufficient attention to the connection between the new word form and its meaning.

Aside from the richness of context, prior/background knowledge (topic familiarity) and the reader's vocabulary proficiency level are of great significance. There are many accounts in the psychological and SLA literature that greater levels of background knowledge and expertise in a given subject matter result in the efficiency of attentional allocation during reading, enable richer analyses and textual interpretations, and, in turn, superior memory performance (Pulido, 2003:236). In simple words, a reader is more successful at lexical inferencing when $\mathrm{s} / \mathrm{he}$ is aware of the topic. Since activation of appropriate knowledge structures stored in long-term memory is necessary to construct and integrate meaning successfully across discourse, it stands to reason that it will also have a strong bearing on the construction of meaning at the textual level. As a result, text recall is enhanced when learners possess and utilize the appropriate background knowledge.

The other significant issue is the reader's vocabulary proficiency level. The stronger vocabulary a reader has, the better s/he is able to understand the text that he interacts with (Chin, 1999:1). In an experiment, Prince (1996:481) comes to the conclusion that advanced learners will make more efficient use of context than weaker learners, both during the study phase and during recall. To conclude, although GFC obviously has an important role to play 
in the overall scheme of vocabulary learning strategies (74\% of Schmitt's (1997) intermediate level L2 learners of English used GFC, and $73 \%$ found it helpful), it cannot solve all reading comprehension, let alone acquisition, problems, and it needs to be supplemented by other vocabulary learning strategies.

\subsubsection{Frequency effect}

Frequency refers to the degree of probability of encountering a word in speech or print. It is obvious that the frequency of occurrence of the unknown words in the text has a significant impact on the retention of word meaning. The main reason given is that the reappearance of a word will strengthen the form-meaning connection in the reader's mental lexicon. In a more technical experiment by Hulstijn, Hollander and Greidanus (1996:327) support was found for the hypothesis that frequency of occurrence will foster incidental vocabulary learning more when advanced second language (L2) readers are given the meanings of unknown words through marginal glosses or when they look up meanings in a dictionary than when no external information concerning the meaning of unknown words is available.

It is a rather complicated task to mention the precise or relative number of words and accordingly exposures in a text required to learn a word. In addition, the number of exposures needed for mastery of a new word lies in many factors such as the salience of the word in the context, the richness of contextual clues, the learner's interest and his/her existing repertoire of vocabulary.

\subsubsection{Incidental (implicit) vs. intentional (explicit) vocabulary learning}

In implicit vocabulary learning students engage in activities that do not focus attention on vocabulary. Incidental vocabulary learning is learning that occurs when the mind is focused elsewhere, such as on understanding a text or using language for communicative purposes (Celce-Murcia, 2001:289). Huckin and Coady (1999) point out that implicit learning cannot be totally incidental as at least some attention must be paid to the input by the learner. The implicit vocabulary learning hypothesis has its roots in Krashen's seminal Input Hypothesis (Krashen, 1989) maintaining that meanings of new words are acquired subconsciously as a result of repeated exposures in a range of contexts, where the conscious focus is not on form, but on the message.

The explicit vocabulary learning hypothesis holds that the employment of a range of vocabulary learning strategies can greatly facilitate and enhance vocabulary acquisition; in this view, learners are seen as active processors of information (Ellis, 1995). From a pedagogically-oriented perspective, the goal of explicit teaching is $\ddot{A}$ "to lead the learner's attention", whereas the aim of an implicit focus on form is "to draw the learner's attention". Moreover, individual tasks can be located along an explicit or implicit continuum, and complex tasks may combine both explicit and implicit subtasks. From a cognitive psychological perspective, explicit learning can be contextualized as a conscious searching, building and testing of hypotheses and assimilating a rule following explicit instruction, whereas implicit learning is characterized by the automatic abstraction of the structural nature of the material arrived at from experience of instance (Hunt \& Beglar, 2005:3).

The following appear to be essentials for successful incidental acquisition to occur (Schmitt and McCarthy, 1997; Groot, 2000): 
* Level of language proficiency (the ability to accurately decode the orthographic form of new words)

* Learner must have large L2 vocabulary (deducing the meaning of an unknown word requires a thorough understanding of the context, which in turn presupposes a large vocabulary)

* Strategic knowledge of inferencing process

* Context must be sufficiently rich in cues

While definitions begin to clarify explicit and implicit learning, questions remain concerning what features of vocabulary and grammar are best learned explicitly or implicitly and how these processes occur. In addition to distinguishing between explicit and implicit instruction, it is also necessary to consider which is more effective for promoting the acquisition of vocabulary knowledge. In fact, there is evidence in recent studies of second language learners that a combined approach is superior to a single learning method. Most researchers have recognized that a well-structured vocabulary programme needs a balanced approach that includes explicit teaching together with activities providing appropriate contexts for incidental learning (Celce-Murcia, 2001:286). Hunt and Beglar (2005:3) in their framework also highlight the point that the most efficient learning involves a carefully selected combination of both explicit and implicit instruction and learning.

Finally, it should be noted that the most important explicit lexical instruction and learning strategies include lexis (word lists), using dictionaries and inferring from context, while the implicit approach primarily and basically involves students in meaning-focused reading. In the preceding sections, inferring from context was discussed. Now, the role of the dictionary and then of meaning-focused reading will be examined.

\section{Dictionaries}

Type of dictionary

Researchers are interested in investigating the part that dictionaries play in the learning of second language vocabulary. The dispute over the kind of dictionaries to be used in the foreign language classroom, and what dictionaries, if at all, should be used has always been an on-going one amongst language instructors and lexicographers. Presently, there is a prevalent view that EFL teachers should discourage students from consulting dictionaries because students' extensive dictionary use can lead to word for word reading (Chin, 1999:3).

Three types of dictionaries are available: bilingual, monolingual, and bilingualized, and these can be found in either paper or electronic form. Both bilingual and monolingual dictionaries have their unique strong points and weaknesses for developing vocabulary knowledge.

Apart from the short and easy-to-understand definitions found in bilingual dictionaries, their strengths are: they can improve the reading comprehension of lower proficiency L2 learners, they assist vocabulary learning at all levels of proficiency (Hunt \& Beglar, 2005:12). On the other hand, bilingual dictionaries 1) encourage translation, 2) foster one-to-one precise correspondence at word level between two languages, and 3) fail to describe adequately the syntactic behaviour of words (Gu, 2003:8). 
In contrast, monolingual learners' dictionaries can be used to build and elaborate learner's vocabulary knowledge, using up-to-date and reliable sentence examples drawn from corpus data that provide information about meaning, grammar and usage (Hunt \& Beglar, 2005:12). The monolingual entry can generally provide more detailed and precise information about idiomatic usage, common collocations, connotations, and register (Laufer \& Hadar, 1997:189).

Since a combination of the good features of both types of dictionaries is attainable, there is considerable interest in the new bilingualized compromise dictionaries. A bilingualized entry typically includes: L2 definitions, L2 sentence information or L1 synonyms of the headword. These hybrid and fused dictionaries essentially provide translations in addition to the good features of monolingual dictionaries. Using bilingualized dictionaries is more efficient than using separate bilingual and monolingual dictionaries, and they are more flexible because beginning and intermediate learners can rely on the L1 translation and advanced learners can concentrate more on the L2 part of the entry (Laufer \& Hadar, 1997; Gu, 2003; Hunt \& Beglar, 2005).

The above types of dictionaries are also available in various electronic forms (software, pocket electronic and online dictionaries). It is obvious that electronic dictionaries (E-dictionaries) are easier and more convenient to use than printed dictionaries. They frequently permit the learners to search multiple sources (grammar, text usage as well as thesaurus), save and review words and definitions. Some e-dictionaries offer advanced searches, provide multimedia annotations, such as illustrations and video that assist in reading comprehension and vocabulary learning (Chun \& Plass, 1996:185).

Regardless of the dictionary selected, learners need to learn how to use it effectively. In order to use a dictionary effectively, it is worth noting that more research is needed on what exactly learners do and how their dictionary strategies influence their learning results.

\section{Dictionary look-up}

Research findings are inconclusive as regards the benefit of dictionary look-up for vocabulary acquisition/comprehension. The purpose of Hulstijn's (1993) study was to examine the connection between look-up behaviour and vocabulary knowledge on the one hand and inference ability on the other hand, taking into account the influence task variables such as reading goal, word relevance and word inferability. The result was that learners did not look up all unfamiliar words, with look-up behaviour most strongly related to the perceived relevance of the word, but only modestly to readers' vocabulary knowledge. Interestingly, the ability to infer word meaning from context was not related to look-up behaviour at all, which suggests that a substantial proportion of good guessers may have been inclined to check their guesses subsequently. Finally, there seems to be no significant difference in lexical knowledge between 'maximalists' (subjects who looked up many words) and 'minimalists' (Hulstijn, 1992, Chun and Plass, 1996).

\section{Meaning-focused reading}

Reading is one of the most important ways that learners gain lexical knowledge incidentally. Recent developments in lexical semantics tell us a lot about vocabulary learning. Concentration on meaning-focused reading will result in incremental increases in vocabulary size, the 
elaboration of lexical knowledge and development of reading fluency. Zimmerman (1997:123) believes that a considerable amount of word learning takes place incidentally through exposure to new words in meaningful contexts. Implicit learning through meaning-focused reading can occur incidentally as a result of learners' engaging in such activities as integrated task sets (a series of tasks requiring the use of multiple skills), narrow reading, rereading, timed and paced readings, intensive and extensive reading (Hunt \& Beglar, 2005:15). Swanborn and Glopper (2002:98) also examine how reading texts for different purposes affects amounts of incidental word learning and then come to the conclusion that only the meaning of unknown words that are relevant for the reading purpose will be derived and recalled. Although these activities deserve greater attention in many EFL classrooms, the investigator intends to place emphasis upon extensive reading as the primary means for implicit learning for two reasons: its potentiality for triggering EFL learners and the fact that it can take advantage of the amount of meaningful input accessible to learners.

\section{Extensive reading}

In extensive reading, learners select and read large amounts of materials that appeal to them and are within their level of comprehension. The core of a meaning-focused input strand of a course is a well-organized, well-monitored, substantial extensive reading programme

... (Nation \& Meara, 2002:40). Shu et al.(1995:79) highlight the point that learning from context through extensive reading might be one of the important sources in children's vocabulary growth. Intermediate and advanced L2 learners enlarge their vocabulary to a great extent through incidental learning during extensive reading (Hulstijn et al., 1996:337).

For extensive reading to be efficient, learners must be frequently exposed to bulky amounts of comprehensible text. Since the knowledge gained from a single encounter with a lexical item is likely to be disremembered unless rapidly followed by another encounter, repeated contextualized exposures are necessary to consolidate and secure word meaning. Harmon (1999:306) advocates the promotion of wide reading as an important vehicle for vocabulary development because students learn words from context during reading. Teachers can promote consolidation through the use of post-reading activities in which learners first notice the target lexis by highlighting, underlining or circling them, and then processing them by classifying, analyzing, or using the items productively (Hunt \& Beglar, 2005:9).

\subsubsection{Glosses and note-taking}

Textual glosses have been used for a long time to facilitate L2 reading; other forms of glosses include pictorial (visual) and aural glosses, and various combinations thereof. In general, there exists a consensus among researchers that glosses facilitate reading comprehension and short-term vocabulary retention (Kost et al., 1999). As for textual glosses, there is a choice of language and form (single-choice or multiple-choice) glossing. Some studies have explored the effectiveness of the different options: Laufer and Shmueli (1997) found that glosses in L1 (Hebrew) led to better retention than L2 (English) glosses. Multiple-choice glossing, while encouraging deeper processing, suffers (in the printed form) from lacking immediate feedback on student errors. This problem can be attended to by using computers, however; Nagata (1999) found multiple-choice glossing with immediate feedback to be more effective than single-choice glossing. 
After getting information about a lexical unit, learners may take notes, in the form of vocabulary notebooks, vocabulary cards, or simply notes in the margins or between the lines (marginal glosses). Note-taking is one of the basic strategies often recommended by researchers in the field of vocabulary learning. Vocabulary cards are invaluable in consolidating primary gains because of their probability, ease of use and number of communicative activities in which they can be used, as well as their potentiality for increasing student's enthusiasm. In a comparative empirical research, Hulstijn et al. (1996:336) conclude that the effect of marginal glosses will be greater than that of dictionary use because readers often do not make use of the dictionary. However, they then refine their conclusion in such a way that when readers do use a dictionary, the incidence of incidental vocabulary learning will be as good as, or even better than, when they are provided with marginal glosses.

\subsubsection{Mnemonics: zeroing in on memory}

Among various other strategies frequently studied in the literature, one that requires a considerable amount of treatment and profound processing is mnemonics. Since vocabulary learning is essentially a memory matter, mnemonics should play a part in foreign language vocabulary learning as well. Mediation strategies - involving the new L2 word in some form of meaningful association - come in two varieties, imagery mediation and semantic mediation, and are examples of deep strategies. Imagery mediation in its plainest sense involves visualizing a mental picture or image of the L2 word in question; the most interesting variant of imagery mediation, however, is the keyword method $(\mathrm{KW})$. $\mathrm{KW}$ has been mainly positively evaluated in the literature and can boast some impressive evidence of superiority over other direct or mnemonic strategies (Gu and Johnson, 1996).

As mentioned above, one of the most studied mnemonics is the keyword method $(K W)$, in which the foreign word is remembered by being linked to a keyword, a sound-like native word (the acoustic link), through an interactive image that involves both the foreign word and the native word (the imagery link). Avila and Sadoski (1996:380) define the keyword method in two stages. First, the FL word is associated with a familiar concrete word (keyword) based on acoustic similarities. The next stage is the production of an imaginal link between the target word and the keyword.

Since in this method the linkages from the vocabulary to a meaningful definition are provided, they will produce enhanced associative recall of definitions. As a result, the mnemonics links, particularly the imagery keyword technique, enable learners to memorize vocabulary more effectively. One of the frequently quoted claims of mnemonics is that people remember better over long periods of time if they have utilized mnemonic aids because they have a way to "get back at the word again" (Ott et al., 1976:45).

Irrespective of the advantages of this method, there exist some limitations:

1) As the keyword is merely an approximation of the L2 form, 'proper' learning of correct L2 phonology and orthography is unnecessarily delayed (although Hulstijn (1997) points out that there are no theoretical reasons to assume KW plays an inhibiting part).

2) It strongly relies on nature of words (KW can only be used for concrete nouns, rarely for abstract ones).

3) The mnemonic approach to vocabulary development emphasizes an unchanging oneto-one relationship between form and meaning. However, a key view in the applied 
linguist's conception of vocabulary is manifold meanings and multiple dimensions of meanings (referential, syntactic, pragmatic, emotional, functional, literary, etc.). Especially in the case of polysemous words, it only helps establish one of the necessary meaning links.

4) Mnemonic devices are much less effective in productive vocabulary learning than in learning to comprehend the L2 because imagery association in the keyword technique allows retrieval of a keyword which is merely an approximation to the L2 form $(\mathrm{Gu}$, 2003:15).

Although the applications of KW (and other mnemonic techniques, for that matter) are limited, its efficiency and value have been sufficiently proven. It is perhaps best seen as a helpful addition and complementary strategy, but not a substitute, for other vocabulary learning strategies.

\subsubsection{Word-formation: focusing on form}

Knowledge of lexical roots (etymological information and morphological origins) can assist in vocabulary development in that it helps students predict or guess what a word means, elucidate why a word is spelt the way it is, and remember the word by knowing how its current meaning develops from its morphological roots. Students should learn to identify morphemes which recur in a number of words and which can help them to identify at least part of the meaning, thus assisting them in guessing from context the meaning of apparently new items (Rivers, 1981:465). Contextual information and word morphology (e.g. word roots, affixes, and inflectional suffixes) are two major sources that readers use to interpret novel words (Mori, 2003:404).

Although most words can be decomposed into root words, prefixes, and suffixes, the degree to which these components specify the meaning of the whole varies widely. Shu et al. (1995:80) introduce two major categories of words. First, the meaning of some words can easily be determined on the basis of the word parts with little or no help from context (morphologically transparent words). Second, at the other extreme are words for which the components contribute almost nothing to the meaning (morphologically opaque words). In general, most words fall in between; although their meanings cannot be derived solely on the basis of word parts, their meanings are likely to be clear when they appear in even a moderately helpful context.

In this regard, two studies by Bogaards (2001:321) underscore the importance of knowledge of form - but not of previously learned meaning - for the learning of new meanings for familiar forms. Then, based on his first experiment, he concludes that totally new single-word units are harder to learn and retain than multiword units of the same meaning but with a form that is made up of familiar words. In another technical study on the effects of semantic and structural elaboration on second language (L2) lexical acquisition, Barcrof (2002:323) provides evidence that increased semantic elaboration (evaluation of an item with regard to its meaning) can inhibit one's ability to encode the formal [phonemic/graphemic] properties of new words. Furtermore, in an interesting experiment Nagy, McClure and Mir (1997:431) state that first language syntactic knowledge influences guesses about the meanings of unfamiliar words in 
a second language context. This effect is found among bilinguals who have experienced a variety of amounts and types of exposure to English.

A learner needs three skills in order to make use of affixation: breaking a new word into parts so that the affixes and roots are revealed; knowing the meaning of the parts; and being able to connect the meaning of the parts with the meaning of the word. Put another way, to make use of word parts, the learner needs to know the most useful word parts of English (20 or so high-frequency prefixes and suffixes are enough initially), needs to be able to recognize them in their various forms when they occur in words and needs to be able to relate the meanings of the parts to the meaning or definition (Nation \& Meara, 2002:46).

\subsection{Learner-dependent vocabulary learning strategies}

From guessing at the first encounter, to possible dictionary use and note taking, to memorizing, encoding, and contextual activation, vocabulary acquisition is a dynamic process involving metacognitive choices and cognitive implementation of a whole spectrum of strategies. Whether and how a learner evaluates the task requirement and whether and how a cognitive strategy is utilized are often dependent more on the learner than on the task.

\subsubsection{Good learners \& poor learners}

Researchers in the VLS (vocabulary learning strategy) area have attempted to identify the ways in which "good" and "poor" learners approach lexical learning. The good learners are more aware of what they can learn about new words, pay more attention to collocation and spelling, and are more conscious of contextual learning. By contrast, the poor learners are generally characterized by their apparent passiveness in learning. Swanborn and Glopper (2002:99) suggest that poor readers are not as able as good readers at adjusting their reading strategies to fit the reading purpose and accordingly learning more affectively from context. In other words, good readers are accordingly good comprehenders and learners who are better skilled at handling vocabulary acquisition tasks. In a similar study, Pulido (2003:239) states that strong readers tend to have more efficient decoding skills and larger sight vocabularies than weak readers. So these outcomes in reading performance can be explained by individual differences and strategies applied in these areas. Gu and Johnson (1996:668) also studied 850 university EFL students in China, and tried to establish how different vocabulary strategies were related to language learning outcomes. Both Pearson's correlation and multiple regression analyses revealed that self-initiation, selective attention, and deliberate activation of newly learned words consistently predicted both vocabulary size and general proficiency. Other predictors of success included contextual learning, dictionary, and note-taking strategies.

\section{Method}

This study significantly profiles issues, strategies, techniques and variables related to vocabulary acquisition in detail. In other words, the investigator tries to critically expand on the concepts largely applied in the field of vocabulary knowledge and acquisition.

This paper also takes maximum advantage of researchers' recent findings and achievements in specific areas of vocabulary acquisition. Therefore, it attempts to present these major 
findings under each of the main areas of study on the topic. It is intended that the research focuses critically on the variables connected to lexical knowledge and sets up a fairly comprehensive framework which includes and takes into account the most important strategies and factors within the vocabulary acquisition context.

In order to conduct the research in a more systematic manner, the researcher specifically takes four prominent variables into account; three from a cognitive model suggested by Flavell (1992), i.e. learner, task, strategy as the general frame of the research as well as the variable of context. The investigator accordingly tries to explain major issues and comments from different dimensions based on recent investigations and achievements connected to each variable.

\section{Discussion}

In a rather comprehensive review of the relevant literature, the factors and variables involved in vocabulary acquisition were critically discussed and analyzed. The crucial notion implied via critical understanding of the materials developed and argued in this study seems to point out the fact that in lieu of seeking the excellent strategies that create the best results, the investigator maintains the relative efficiency of each strategy. In addition, the organic notion underlying this study is that the most effective and efficient lexical development will occur in multifaceted curriculums that attain a pedagogically sound equilibrium between explicit and implicit activities for L2 learners at all levels of their development.

Finally, in order to avoid repeatedly explaining very similar research findings already mentioned fully in various strategies and approaches to vocabulary acquisition, the researcher in the discussion part goes on to outline the most important implications deriving from the issues noted within the paper. Furthermore, it will touch on topics needed for potential future research.

A. The rough focus of research in the linguistics tradition regarding vocabulary acquisition has largely centered on vocabulary learning (what is learned/to be learned; productoriented view) rather than acquisition (how is vocabulary learned, process-oriented perspective) (Crow, 1986; Meara, 1980).

B. From a psychological standpoint, memory strategies have occupied the major share of attention in vocabulary acquisition, probably for the reason that this learning/ acquisition process has largely been taken as a memory problem.

C. Much of the stress on incidental vocabulary learning has zeroed in on how helpful incidental learning is and how much can be learned incidentally, often ignoring the fact that a lot can be learned intentionally and by design during reading with the help of strategies (e.g. inferring from context, dictionary use, note-taking, as well as intentional repetition).

D. Accessible research on vocabulary learning strategies does indicate a tendency that good learners act better that poor ones, but the field would definitely benefit from a clearer focus on how precisely learners learn lexical units and how their strategies are related to acquisition outcomes (Schmitt, 2000).

Research efforts have largely been directed towards discovering and supporting the best strategy for vocabulary retention. In reality, learners tend to utilize a variety of strategies in 
combination. Therefore, as highlighted in this paper, it seems highly preferable to seek to design a multifaceted framework with a pedagogically sound equilibrium that takes advantage of the positive and appropriate strengths of each strategy in a due and sensible time and at relevant level.

\section{Concluding remarks}

The major goal of this study is to investigate and review the effects of learning strategies on EFL vocabulary acquisition during recent years. Vocabulary acquisition can be best conceived as a process in which L2 learners negotiate word meaning from a text level to a word level. This shift is necessary so that the learner can form a mental connection between the word form and his/her meaning premise (Mohseni-Far, 2006:162).

Word knowledge has linguistic, psycholinguistic, and sociolinguistic aspects. Lexical competence is far more than the ability to define a given number of words; it entails knowing a great deal about each word, including information about its general frequency of use, the syntactic and situational limitations on its use, its generilizability, its collocational probabilities, its core form, its derived forms, and its semantic features. The process by which learners acquire this information appears to take place gradually over a long period of time, is very complex, and is quite difficult to investigate. In conclusion, a lot of work has been done to find overall patterns of strategy use. However, the choice, use, and effectiveness of vocabulary learning strategies very much depend on the task (e.g. breadth vs. depth), the learner (e.g. cognitive and cultural styles of learning, motivation), and the context. Future research, therefore, needs a more technical and closer approach that takes all the aforementioned features into account.

To put it in operational terms, word knowledge includes the ability to recall meaning, infer meaning, comprehend a text, and communicate orally. No single approach can address all of these skills; when learners receive input about vocabulary only from reading or only from the use of lists, drills, or skill-building activities, they have not addressed the range of skills needed for word use. Effective approach to word learning should be multifaceted and comprehensive in what they require of the learner and rich in what they reveal about the target words. In a nutshell, the overall presumption must be that there is no simple answer to the key question of what the most efficient method/strategy of L2 word learning/acquisition is/should be. It depends very much on variables like degree of L1-L2 equivalence of the words to be learned, the intensity (both qualitative and quantitative) of processing, the age and cognitive level of the learner, the quantity and quality of rehearsal practice and variables discussed through this research. As a result, more experimentation systematically and analytically controlling these variables is required to collect data that will provide more insight into their relative importance and efficiency. Out of the meticulous examination of obtained results, a flexible, multi-purpose and eclectic skeleton and curriculum needs to be designed and developed so as to take best advantage of the strong points and effective potential of each strategy at its due time of utilization and which best fits with the existing overall characteristics of the pertinent task, context and learner. Therefore, a successful cognitive task performance (i.e. vocabulary acquisition) will be achieved within such a flexible, multiple-purpose and highly interactive framework. 


\section{REFERENCES}

Avila, E. \& M. Sadoski. (1996). Exploring new applications of the keyword method to acquire English vocabulary. Language Learning, 46, 379-395.

Barcrof, J. (2002). Semantic and structural elaboration in L2 lexical acquisition. Language Learning, 52, 323-363.

Bogaards, P. (2001). Lexical units and the learning of foreign language vocabulary. Studies in Second Language Acquisition, 23, 321-343.

Celce-Murcia, M. (2001). Teaching English as a Second or Foreign Language. United States of America: Heinle \& Heinle.

Chin, C. (1999). The effects of three learning strategies on EFL vocabulary acquisition. The Korea TESOL Journal, 2, 1-29.

Chun, D.M. \& J.L. Plass. (1996). Effects of multimedia annotations on vocabulary acquisition. The Modern Language Journal, 80, 183-212.

Cook, V. (1991). Second Language Learning and Language Teaching. London: Edward Arnold.

Crow, J. T. (1986). Receptive vocabulary acquisition for reading comprehension. The Modern Language Journal, 70, 242-250.

De la Fuente, M.J. 2002. Negotiation and oral acquisition of L2 vocabulary. Studies in Second Language Acquisition, 24, 81-112.

Ellis, N.C. (1995). The psychology of foreign language vocabulary acquisition: Implications for CALL. Computer Assisted Language Learning, 8, 103-128.

Ellis, R., Y. Tanaka \& A. Yamazaki. (1994). Classroom interaction, comprehension, and the acquisition of L2 word meanings. Language Learning, 44, 449-491.

Flavell, J.H. (1992). Metacognition and cognitive monitoring. In T.O. Nelson (ed.), Metacognitive: core readings, 3-8. Boston: Allyn and Bacon.

Groot, P.J.M. (2000). Computer assisted second language vocabulary acquisition. Language Learning \& Technology, 4, 60-81.

Gu, Y. (2003). Vocabulary learning in a second language. TESL-EJ, 7, 1-26.

Gu, Y. \& R.K. Johnson. (1996). Vocabulary learning strategies and language learning outcomes. Language Learning, 46, 643-679.

Harmon, J.M. (1999). Initial encounters with unfamiliar words in independent reading, R.T.E., 33, 304-338.

Henriksen, B. (1999). Three dimensions of vocabulary development. Studies in Second Language Acquisition, 21,303-317.

Huckin, T. \& J. Coady. (1999). Incidental vocabulary acquisition in a second language: A review. Studies in Second Language Acquisition, 21,181-193.

Hulstijn, J.H. (1992). Retention of inferred and given word meanings: experiments in incidental vocabulary learning. In P. Arnaud and H. B’ejoint (eds), Vocabulary and Applied Linguistics, 113-125. London: Macmillan.

Hulstijn, J.H.(1993). When do foreign-language readers look up the meaning of unfamiliar words? the influence of task and learner variables. The Modern Language Journal, 77, 139-147.

Hulstijn, J.H. (1997). Mnemonic methods in foreign language vocabulary learning: theoretical considerations and pedagogical implications. In J. Coady and T. Huckin, (eds), Second Language Vocabulary Acquisition, 203-224. Cambridge: C.U.P.

Hulstijn, J.H., M. Hollander \& T. Greidanus. (1996). Incidental vocabulary learning by advanced foreign language students: the influence of marginal glosses, dictionary use, and reoccurrence of unknown words. The Modern Language Journal, 80, 327- 339. 
Hulstijn, J.H. \& B. Laufer. (2001). Some empirical evidence for the involvement load ypothesis in vocabulary acquisition. Language Learning, 51, 539-558.

Hunt, A. \& D. Beglar. 2005. A framework for developing EFL reading vocabulary. Reading in a Foreign Language, 17, 1-31.

Kost, C.R., P. Foss \& J.J. Lenzini. (1999). Textual and pictorial glosses: effectiveness on incidental vocabulary growth when reading in a foreign language. Foreign Language Annals, 32, 89 97.

Krashen, S.D. (1989). We acquire vocabulary and spelling by reading: additional evidence for the input hypothesis. The Modern Language Journal, 73, 440-464.

Laufer, B. \& L. Hadar. (1997). Assessing the effectiveness of monolingual, bilingual, and "bilingualized" dictionaries in the comprehension and production of new words. The Modern Language Journal, 81, 189-196.

Laufer, B. \& J. Hulstijn. (2001). Incidental vocabulary acquisition in a second language: the construct of task-induced involvement. Applied Linguistics, 22, 1-26.

Laufer, B. \& K. Shmueli. (1997). Memorizing new words: Does teaching have anything to do with it? RELC Journal, 28, 89-108.

Lawson, M.J. \& D. Hogben. (1996). The vocabulary learning strategies of foreign language students. Language Learning, 46, 101-135.

Meara, P. (1980). Vocabulary acquisition: a neglected aspect of language learning. Language Teaching and Linguistics Abstracts, 13, 221-246.

Mohseni-Far, M. (2007). Techniques and strategies utilized for vocabulary acquisition: the necessity to design a multifaceted framework with an instructionally wise equilibrium. Porta Linguarum, $8,137-152$.

Mori, Y. 2003. The roles of context and word morphology in learning new Kanji words. The Modern Language Journal, 87, 404-420.

Mohseni-Far, M. (2006). Techniques utilized for vocabulary acquisition. Language Forum, 32, 147-165.

Nagy, W., E.F. McClure \& M. Mir. (1997). Linguistic transfer and the use of context by SpanishEnglish bilinguals. Applied Psycholinguistics, 18, 431-452.

Nation, I.S.P. (1990). Teaching and Learning Vocabulary. Boston, MA: Heinle \& Heinle.

Nation, P. \& P. Meara. (2002). Vocabulary. In N. Schmitt (ed.), an Introduction to Applied Linguistics, 35-54. London: Arnold.

Nagata, N. 1999. The effectiveness of computer-assisted inteactive glosses. Foreign Language Annals, 32, 469-479.

Newton, J. (2001). Options for vocabulary learning through communication tasks. ELT, 55, 30-37.

Ott, C.E., R.S. Blake \& D.C. Butler. (1976). Implications of mental elaboration for the acquisition of foreign language vocabulary. IRAL, XIV, 37-48.

Prince, P. (1996). Second language vocabulary learning: the role of context versus translations as a function of proficiency. The Modern Language Journal, 80, 478-493.

Pulido, D. (2003). Modeling the role of second language proficiency and topic familiarity in second language incidental vocabulary acquisition through reading. Language Learning, 53, 233-284.

Pulido, D. (2004). The relationship between text comprehension and second language incidental vocabulary acquisition: a matter of topic familiarity. Language Learning, 54, 469-523.

Rivers, W.M. (1981). Teaching Foreign-Language Skills. Chicago: The University of Chicago Press. 
Rubin, J. (1987). Learner strategies: theoretical assumptions, research history and typology. In A.Wenden and J. Rubin (eds), Learner Strategies in Language Learning, 15-30. New York: Prentice Hall.

Schmitt, N. (1997). Vocabulary learning strategies. In N. Schmitt and M. McCarthy (eds), Vocabulary: Description, Acquisition and Pedagogy, 199-227. Cambridge : C.U.P.

Schmitt, N. (2000). Vocabulary in Language Teaching. Cambridge: Cambridge University Press.

Shu, H., R.C. Anderson \& H. Zhang. (1995). Incidental learning of word meanings while reading: a Chinese and American cross-cultural study. Reading Research Quarterly, 30, 79-95.

Swanborn, M.S.L. \& K.D. Glopper. (2002). Impact of reading purpose on incidental word learning from context. Language Learning, 52, 95-117.

Wenden, A. 1987. Conceptual background and utility. In A. Wenden and J. Rubin (eds), Learner Strategies in Language Learning, 3-13. New York :Prentice Hall.

Zimmerman, C.B. (1997). Do reading and interactive vocabulary instruction make a difference? an empirical study. TESOL Quarterly, 31, 121-140.

Acknowledgement: I would like to express my deep gratitude on Professor Ismail Baroudy's thought-provoking and continuous support, my dear professor to his constant guidance I am greatly indebted. I thank so much Professor Daniel Madrid and anonymous evaluators for their meticulous evaluation and sincere attention toward my paper. Finally, a special thanks goes to Mrs. Rezvan Abol-Nejadian, B.A., for supporting my research and encouragement, I am also grateful to her for helping me complete the work successfully. 